\title{
Canadian Inuit subsistence and ecological instability- if the climate changes, must the Inuit?
}

\author{
George W. Wenzel \\ Department of Geography, McGill University, Montréal H3A 2K6, Canada
}

\author{
Keywords \\ Arctic Canada; climate change; \\ environmental politics; food subsistence \\ system; Inuit; social economy. \\ Correspondence \\ George W. Wenzel, Department of \\ Geography, McGill University, Montréal H3A \\ 2K6, Canada. E-mail: wenzel@geog.mcgill.ca \\ doi:10.1111/j.1751-8369.2009.00098.x
}

\begin{abstract}
Considerable attention has been devoted to the possible effects of global climate change on the environment of the circumpolar world. With regard to the Inuit, the aboriginal culture of Arctic Canada, research interest has focused principally on the vulnerability of the hunting and harvesting component of the traditional food system, otherwise frequently referred to as the subsistence system, if wild terrestrial and marine resources become less available. Although also concerned with the traditional Inuit food economy, this paper concentrates on the customary institutional mechanisms by which the Inuit distribute and share the products obtained from hunting. After analysing this social economy, a review of the data on recent climate-related range changes of a number of Arctic animal populations is carried out, in terms of how projected environmental changes may affect this other aspect of Inuit subsistence. After tentatively concluding that some species substitution and/or replacement will occur, the final aspect of the paper considers the potential for the possible exclusion of these "replacements" as a result of the political aspect of climate change.
\end{abstract}

One Baffin Island summer night, Jamasee Qillaq, of Clyde River, and I were watching the sea ice around the island where we were camped erode, when, just beyond the worthwhile shooting range, a pod of narwhal (Monodon monoceros) cruised along the deteriorating floe edge. I mentioned to him and several other hunters that the idea of global climate change was becoming an important topic among northern scientists, and that perhaps we were seeing one of its signs. Jamas gave this some thought before saying, "If this is global warming, we'll love it".

Our narwhal watch was on 18 July 1992, and no person at Clyde River could remember open water, let al.one narwhal, appearing so early along the eastern Baffin Island coast. In fact, in the previous 20 years, the earliest that narwhal hunting had commenced was in August, and we each recalled that there had been three "summers" of those 20 when the ice had never cleared, and there had been no narwhal hunt at all.

I thought at the time that our mid-July whale watch was an anomaly, a belief that was bolstered by another "no-summer" summer the following year. In fact normalcy returned for the rest of the decade, with open water only arriving in early August. (To the Inuit at Clyde
River, "open water" means that they are able to freely navigate a boat from Patricia Bay, where the village is located, for approximately $20 \mathrm{~km}$ to the adjacent Clyde Inlet.) Then, in the year 2000 whaling again began in mid-July, whereas 2001 saw Clyde hunters take a narwhal on 7 July, and whaling has begun sometime in the first two weeks of July every year since 2000.

\section{Focus}

The impact of climate on the Inuit has been a dominant theme in Eskimo anthropology since Franz Boas (1888) first undertook research on Baffin Island. Today, when the study of hunter-gatherers has become a virtual subdiscipline within anthropology, the "attribute" that still sets the Inuit apart from other hunting peoples is the same one that struck Boas (and virtually every other non-Inuit visitor to the Canadian Arctic, from Martin Frobisher to the "jet-in/jet-out" Midnight Sun tourist): how can any people adapt to an environment epitomized by a climate often described as cold or colder.

The relationship between climate and Inuit ecological activities is almost too obvious. The Inuit are very much marine mammal hunters, and the most referenced 
passage in Boas' seminal "The Central Eskimo" is about the link between sea ice, ringed seal (Phoca hispida) distribution, and Inuit hunting and settlement. And, as wildlife still contributes significantly to the Inuit food economy, one part of this paper will address the continued importance of niqituinnaq ("real food") in the contemporary subsistence system. Indeed, how a warmer environment is affecting Inuit hunters and wild resource production has become a central facet of climate-related social scientific research.

However, the main focus will be on the other, often forgotten, component of Inuit subsistence, namely how the food hunters produce is transferred to those who need it. As important as obtaining a better grasp on how environmental change through climatic warming may affect the material aspects of Inuit resource production, it is equally important to consider the possible effects of environmental instability on the socio-economic relationships that order who gets what and when. In no small way, it is this second aspect that makes subsistence as practiced by Inuit a social, as well as economic, adaptation.

With regard to generating hypotheses, or at least envisioning scenarios, about climate change, we have the benefit of the archaeology and palaeoclimatology that has been performed in the North American Arctic over the past 40 years (Maxwell 1985; McGhee 1996; Mann et al. 1999; McBean et al. 2005: 52-54). Much of this research has helped answer questions about how climate has influenced Inuit ecological adaptation and contributed to change in Inuit culture over the last 1000 years. Thus, in the first section of the paper, a brief review of the recent (roughly over the last millennium) record of climateinduced environmental change, with respect to how it has influenced Inuit resource strategies and use, is offered.

Unfortunately, with respect to the social economy of the Inuit food system - that is, how a seal, caribou (Rangifer tarandus) or whale were shared among cooperating hunters or between villages 500 or 1000 years agoneither the palaeoclimatological nor archaeological records are especially revealing (for an ethnographicallyderived reconstruction of social and economic organization in Thule culture, however, see Savelle \& Wenzel 2003).

The heart of the paper is concerned with the possible socio-economic impacts to Inuit subsistence culture that may accompany large-scale biophysical change in the north, and the non-Inuit political responses to such change. This focus is important, as discussions about Inuit subsistence often reduce the topic to hunting alone, thereby neglecting the social reality of the food system. Without the recognition that subsistence involves both the capture of needed resources and the customary distribution of this production to those in need, an important aspect of Inuit cultural ecological adaptation, and what it may reveal about Inuit adaptive capacity, is lost.

This approach will also complement the extensive work being carried out on the vulnerability of Inuit hunting to changes in the biophysical environment (see Ford et al. 2006; Ford et al. 2008), to changes in sea-ice quality, to new weather patterns and to shifts in the availability or even disappearance of traditional dietary items.

\section{Inuit subsistence and climate: the last 1000 years}

Data from palaeoclimatology, physical oceanography and biology, as well as archaeology, regarding two major past climatic shifts together offer insights into how environmental change affected Inuit material subsistence and cultural adaptation. The important episodes are the NeoAtlantic Period (also known as the Medieval Warm Period), ca. 1000-1300 CE, and the Neo-Boreal Period (or Little Ice Age), which lasted from ca. 1550 to $1850 \mathrm{CE}$ (Vasari et al. 1972; Andrews \& Andrews 1979; Lamb 1982; Grove 1988).

Data from northern Europe, Iceland and the eastern Arctic indicate that during the Neo-Atlantic Period, temperatures across the North Atlantic region were at least $2{ }^{\circ} \mathrm{C}$ above the annual average that prevailed in the eastern Arctic through most of the several centuries prior to 900-1000 CE. It seems that it was only towards the middle of the last century that surface temperatures for the eastern Canadian Arctic and Greenland approached those that occurred during the earlier warm period (Dyck et al. 2007).

Conversely, the Little Ice Age that followed the NeoAtlantic involved a significant cooling of this region, with the most pronounced thermal effect occurring in the far north during the summer. Data from north-western and middle Europe suggest that summer temperatures averaged at $0.5-0.8^{\circ} \mathrm{C}$ less than the average for the 20th century. Further north, notably in Scandinavia, the first half of the 17th century saw 13 summers that were at least $1^{\circ} \mathrm{C}$ colder than the estimated average for the preceding century (Pfister 1988; Briffa et al. 1990).

These episodes also produced large-scale negative feedback in the American Arctic ecosystem. The changes that took place in the physical and biological subsystems of the north in turn correlate with climate-related adaptive adjustments by the Inuit (see Dekin 1972; Barry et al. 1977; Maxwell 1985), with respect to resource emphasis, settlement pattern and geographic mobility. 
The most discussed episode, at least with regard to Inuit environmental adaptation, is the Neo-Atlantic, which warmed the North American polar stage from the Chukchi Sea to West Greenland. This warming, beginning around 1000 CE (McBean et al. 2005), had the important consequence of precipitating a radical spatial and temporal reduction in the extent of annual sea ice across the central and eastern portions of the Canadian Arctic (or what is today the Territory of Nunavut).

In essence, much of the Canadian North, including Hudson Bay, the Northwest Passage and portions of the Canadian Arctic Archipelago, experienced prolonged periods of open water (i.e., longer "summers"), as compared with the period from the 1960s to the 1980s. These periods were characterized by a much reduced level of sea ice, if not a complete absence of it in some areas. This change in the ice regime of the north, from brief annual open-water seasons to long, nearly ice-free ones, afforded an extensive new range to bowhead whales (Balaena mysticetus), and presumably to other migratory marine mammals, like narwhal and white or beluga whales (Delphinapterus leucus), which were formerly prevented from penetrating into the waters of the Canadian Central and High Arctic by the nearcontinuous ice cover.

This summer habitat and range expansion of 40-tonne bowhead whales into much of the Canadian Arctic (with animals moving eastwards from the Chukchi Sea and westwards from the North Atlantic) was an especially important catalyst for the eastwards migration of Alaskan Thule people, ancestral to modern Inuit, enabling Thule hunters to follow their main resource. Already possessing technologies adapted to exploit this largest Arctic animal, and with several centuries of whale-hunting experience, Thule migrants rapidly displaced the late Palaeo-Eskimo (Dorset Culture) populations that had occupied almost all of the Canadian North and Greenland for the preceding two millennia.

In barely two and a half centuries, Thule culture, with its megafauna base, was established along the coasts of what are today the Northwest Territories, Nunavut, Greenland, Nunavik and Labrador-the places that are today home to the Inuit. Although the Thule culture of hunting whales only lasted for the few centuries in which this warming allowed marine megafauna to pass into and through the Canadian Arctic, virtually all of the technological adaptations that the Qallunaat (non-Inuit) world associates with Inuit traditional culture, including dog traction and sled, the umiaq (the large open-skin boat still used to hunt whales in North Alaska) and the qayaq, are legacies from these ancestral Inuit.

As dramatic as the environmental changes, and associated Thule adaptation, of the Neo-Atlantic were, the following Little Ice Age, with between four and five centuries of very much colder weather than present-day conditions, is the reason why the Inuit culture that Europeans met as they quested for a Northwest Passage looked as it did. During this cooling, the long summers of almost ice-free open water disappeared, and, except on the western and easternmost fringes of the Inuit area (respectively, north-west Alaska and Labrador), so did bowhead whales.

This return to deep cold is in many ways as important to understanding Inuit adaptive capacity as was the preceding warm period, for the whole tenor of Thule-based Inuit life, developed during "warm Arctic" conditions, underwent equally large-scale change in this period. For instance, the pattern of Inuit winter settlement across much of Nunavut changed from the semisubterranean whalebone and boulder dwellings of Thule culture to the snow igliuk ("igloo") that was so fascinating to the first European explorers. Likewise, smaller, extended family encampments of 20 or so people replaced the large Thule villages that could only be supported by bowhead hunting.

Above all, the winter food security that came with the harvesting of 20- and 30-tonne whales was gone, also removing the large supplies of blubber for fuel and bone for building that successful hunts ensured. Instead, Inuit culture transitioned into what McGhee (1972: 40) has somewhat over-generally termed a "Netsilik adaptation". Extending geographically across the North American Arctic from the Mackenzie Delta eastwards, this adaptation depended on exploiting a variety of seasonally available smaller prey species, chiefly caribou in summer, ringed seals through the winter and anadromous Arctic char during their spring and autumn migrations between freshwater and the ocean. Although sea mammals like walrus (Odobenus rosmarus), beluga whales and narwhal were not neglected, their capture, especially along the ice clogged central Arctic coast, was not likely to have been a regular component of Little Ice Age Inuit subsistence.

Overall, the Inuit became less sedentary, because the resource suite upon which they had to depend was now composed of smaller game that was highly mobile and seasonally restricted. No longer could a single bowhead hunt be the sole source of the food, fuel, house and sled materials needed by the Inuit.

\section{The Nunavut economy}

An economy, as defined by Lonner (1980: 2), is the structured arrangements and rules that ensure "material goods and specialist services are provided in a repetitive fashion". Further, he views subsistence as "a highly 
specialized mode of production and distribution of not only goods and services, but of social forms" (1980: 5).

A detailed discussion of the economy of modern Nunavut is well beyond the scope of this presentation (for detailed analyses of the Inuit social economy, see Damas 1972; Wenzel 1991, 1995, 2000). Suffice it to say that, other than in the capital of the territory, Iqaluit, or main regional government centres such as Arviat and Cambridge Bay, the term "subsistence", as used by Lonner (1980), accurately describes the situation for many Nunavummiut (Nunavut Inuit).

In general, the economic reality of small communities across Nunavut is that the Inuit live in a mixed economy, in which traditional and non-traditional resourceswildlife, and money for some imported foods, but especially for the tools needed in hunting-must necessarily be integrated. And, although it may at first seem incongruous to link traditional subsistence and money, or Inuit ecological adaptation and economy, the changes to Canadian Inuit life that began in the mid-20th century have made these relationships inevitable.

The need for money relates to changes in the Inuit settlement pattern that began in the 1950s because of Canadian Government social policies (see Damas 2002). Nearly all of the communities present now on the map of northern Canada only existed prior to the mid-point of the last century as trading, police and missionary establishments, from which the Inuit were discouraged from living. Then, as Canadian government policy shifted to the provision of health care, housing and education for the Inuit, the Inuit were actively encouraged to concentrate around the regional centres where these services were being established.

This shift from many small, dispersed extended-family villages to a few large settlements, where hundreds of Inuit could be served, carried with it effects on Inuit subsistence capabilities, because these centralized communities were not chosen for convenient access to good hunting. This situation was considerably different from that of the indigenous villages, which were situated for ease of harvesting, and which were also mobile. Thus, dog team-equipped hunters found themselves having to travel further, remain away longer, and were still less efficient and effective in their pursuit of food, as the travel time for winter seal hunting on Baffin Island and the central Arctic Coast doubled and tripled, respectively. Additionally, the harvesting situation was made even worse as resettlement meant more hunters were concentrated in smaller areas.

Hunting circumstances only eased when the snowmobile achieved widespread acceptance. Relatively inexpensive when first introduced, these machines allowed hunters in places like Clyde River, eastern Baffin Island, to reduce the time required to travel to their prime winter seal hunting areas from two or three hours by dog team to barely an hour. With the snowmobile, the Inuit could continue to produce high-quality food and secure the money for snowmobiles, ammunition and imported staples like flour and sugar, by selling sealskins no longer needed for clothing.

As Fienup-Riordan has observed, monetary income is "the means to accomplish and facilitate the harvest, and not an end in itself" (1986: 314). Hence, money is important, because for traditional resources to be captured effectively (see Wenzel 1989, 1991), even the most traditional hunter must have sufficient money to operate and maintain, not to mention periodically renew, a complex and expensive set of tools that include snowmobiles, firearms and outboard engine-equipped boats. And, although subsistence food production is generally perceived by the non-Inuit to be the endeavour of individuals, when looked at from the point of view of the Inuit, subsistence is about provisioning all those who need food.

As much as hunting remains the production mainstay of the Inuit subsistence, the other aspect of the system, i.e., the allocation of food, and with the modernization of hunting, money and equipment, is as important as ever. This is because traditional foods, although plentiful, require a considerable investment of time by hunters, a reality that sometimes conflicts with the demands of waged employment. This part of Nunavummiut economic practice also remains very much traditional in the way it is organized, and in its overall goal, although this is perhaps less obvious today than even 30 or 40 years ago (Wenzel 1995, 2000; Wenzel \& White 2001).

The ways by which Inuit allocate subsistence goods, both traditional and modern, are referred to as ningiqtuq (Damas 1972; Wenzel 1995). Ningiqtuq is not a single or simply defined process. Generally translated as "to share", it is a web of social mechanisms that frame and guide Inuit economic behaviour. Through it, the Inuit successfully transfer and redistribute traditional resources like seal meat and maktaaq (whale skin), termed niqituinnaq ("real food"), and the equipment and money needed for hunting. Socially based in kinship and co-residence (see Table 1), it maintains these critical flows between individuals, households and, through extended families (ilagiit), across whole communities (even, at times, between communities). As the Inuit often note, no one, whatever their circumstances, need go without food or shelter.

Given the primacy of kindred and community, ningiqtuq is a set of economic practices that is inseparable from the social fabric of Inuit society. In point of fact, the rules 
Table 1 Inuit ningiqtuq interaction sets, based on research conducted by the author at Clyde River and Resolute Bay, Nunavut (see Wenzel 2004).

\begin{tabular}{|c|c|c|}
\hline Set type & Flow direction & Inuktitut referent \\
\hline \multirow[t]{6}{*}{ Traditional } & $\begin{array}{l}\text { 1a isumataq } \leftarrow \text { ilagiit subordinates } \\
\text { (from hunters to male family head) }\end{array}$ & tugagaujuq ${ }^{a}$ \\
\hline & $\begin{array}{l}\text { 1b isumataq } \rightarrow \text { ilagiit subordinates } \\
\text { (redistribution to any family member) }\end{array}$ & tigutuinnaq ${ }^{\mathrm{a}}$ \\
\hline & 2 father-in-law $\leftarrow$ son-in-law & tugagaujuq \\
\hline & $\begin{array}{l}3 \text { isumataq } \rightarrow \text { community } \\
\text { (generalized redistribution to non-kin) }\end{array}$ & nirriyaktuqtuq/minatuq (communal) \\
\hline & 4 between unrelated young and elders & nalaktuq-related \\
\hline & $\begin{array}{l}5 \text { between same-generation non-kin } \\
\text { (generally between elders) }\end{array}$ & inviting in and "gifting" \\
\hline \multirow[t]{3}{*}{ Modern } & 6 between unrelated hunters & uummajusiutiit \\
\hline & $\begin{array}{l}7 \text { angijukak } \leftarrow \text { unrelated hunters } \\
\text { (for instance, boat owners and crew) }\end{array}$ & taliqtuq \\
\hline & $\begin{array}{l}8 \text { angijukak } \rightarrow \text { community } \\
\text { (analogous to } 3 \text {, but without the family component) }\end{array}$ & nirriyaktuqtuq (communal) \\
\hline
\end{tabular}

aTugagaujuq (1a) and tigutuinnaq (1b) are complementary, and participants are generally referred to as being niqiliriiq (sharers of food): such transfers are between individuals.

Table 2 Sociocultural aspects of ningiqtuq, based on research conducted by the author at Clyde River and Resolute Bay, Nunavut

\begin{tabular}{|c|c|c|c|}
\hline Social context & Behavioural directive & Form & Scope \\
\hline \multicolumn{4}{|c|}{ Intra-ilagiit (extended family) } \\
\hline $1 a$ & ungayuk (solidarity-affection) & akpallugiit & inviting guests in (typically same generation non-kin) \\
\hline $1 b$ & ungayuk & $\begin{array}{l}\text { quaktuaktuq/niqisutaiyuq/ } \\
\text { paiyuktuq }\end{array}$ & $\begin{array}{l}\text { food gifts to close affines and non-kin (generally } \\
\text { restricted to elders) }\end{array}$ \\
\hline $1 c$ & ungayuk & niqitatianaq & uummajusiutiit ("partnered” hunters) \\
\hline \multicolumn{4}{|c|}{ Intra-ilagiit (extended family) } \\
\hline $2 a$ & nalaqtuk (respect-obedience) & niqiliriiq & tugagauyuk-tigutuinnaq ${ }^{\text {a }}$ complementary \\
\hline $2 b$ & nalaqtuk & nirriyaktuqtuq & restricted commensalism \\
\hline \multicolumn{4}{|c|}{ Inter-Ilagiit/community } \\
\hline 3a & ungayuk & nirriyaktuqtuq & open commensalism \\
\hline $3 b$ & ungayuk & minaqtuq & open distribution of stored food \\
\hline $3 c$ & nalaqtuk & katujiyuk & transfer within task groups \\
\hline
\end{tabular}

aSee Table 1.

that mediate virtually all aspects of Inuit interpersonal life also direct ningiqtuq (see Damas 1963; Heinrich 1963; Wenzel 1981). In no small sense, the Inuit economy is Inuit culture.

This mutuality (Table 2) is reflected in the multilevel nature of ningiqtuq, encompassing as it does socioeconomic relationships as basic as a pair of men seal hunting (Uummajusiutiit), to the distribution of food surplus, and the return, from large game like walrus, across an entire community (minaqtuq, nirriyaktuqtuq). In functional terms, virtually every form of sharing encompassed by the concept of ningiqtuq has at its root a social, rather than an "economic", referent, beginning with the ilagiit, or extended family, where all are niqiliriiq (literally, "those who share food"). This latter concept has importantly expanded to cope with the more complex circumstances of the centralized communities that have grown through government policy.
The reason for presenting this review is to dispel the false notion that Inuit subsistence is the sum of seals or caribou caught. Rather, Inuit subsistence in the past and today is not only about the production of food, but is equally about all of the Inuit behaviours (see Damas 1972; Wenzel 1995, 2000; Collings et al. 1998) that provide individuals with the security of a wellfunctioning economy à la Lonner (1980: 5).

\section{Climate change and the subsistence system}

Although there is considerable concern about what global climate change may portend for the Inuit as users of wildlife (see, for example, Ford et al. 2006), the evidence available about Inuit adaptive responses to the last major climatic upswing (and subsequent deep cooling) suggests that a warming Arctic need not present an insurmountable threat to the subsistence system. After all, the Neo- 
Atlantic spurred an amazing cultural expansion, which saw the forebears of the modern Inuit move eastwards from North Alaska, and travel more than $8000 \mathrm{~km}$ to the furthermost reaches of Greenland in barely a few centuries, as they replaced a Palaeo-Eskimo cultural tradition that was nearly 2000 years old.

Or this might be the case if the environmental problems to which the Inuit must adapt were limited to biophysical change, as it was for Thule-culture hunters and their post-Neo-Atlantic Period descendants. However, Inuit adaptive options to future ecological change will necessarily be, and are already being, affected by an "environmental dynamic": the politics of global warming. Although the Inuit living from the Mackenzie Delta to Baffin Island, and from Arviat on Hudson Bay north to the High Arctic Grise Fiord, use tools that have their origin in Thule culture, and snowmobiles and rifles, to continue a "Netsilik-type" hunting adaptation for seal, polar bear, narwhal and caribou, the Arctic is no longer an environment in which the Inuit are the sole actors. Today, this other environmental dimension may test the economics and economy of subsistence at least as much as any shifts in the ranges or even the disappearance of important food species.

The capacity of the Inuit to respond successfully to natural environmental change is not limited to evidence of Inuit adaptation in the distant past. The work of Vibe (1967) on the effect of climate change on northern biota and Inuit resource use in West Greenland between 1800 and 1950 offers an important recent window. Using 150 years of Danish colonial meteorological and commercial trading records, Vibe correlated the episodes of warming and cooling that occurred over this century and a half span with the rise and fall in the capture of two critical species for Inuit, ringed seals and polar bears (Ursus maritimus), noting especially the relationship between sea ice, ringed seals and polar bears. He then compared these data with the observations available on sea ice conditions during this period, and noted that at the times when the local climate ameliorated, causing a reduction in the annual duration and, presumably, areal extent of the ice, the capture of both species, as reflected in official trading records, severely declined (Vibe 1967: 51-54, figs. 32, 34; see also Stirling \& Øritsland 1995). These unique records led him to conclude that ringed seal pup production suffers when increased temperatures destabilize spring sea ice, and that this, in turn, affects polar bear populations.

This change in the physical system, and the consequent decline in the availability of ringed seals and polar bears, which precipitated a drastic fall in Inuit trading as the ranges of both species were pushed northwards, is similar to predictions about how the projected warming trend will affect Inuit access to subsistence species in the future. However, Vibe's work also indicates that Greenland Inuit adapted to the loss of ringed seals and polar bears by increasing their harvests of narwhal and harp seal (Phoca groenlandica) (Vibe 1967: figs. 42, 44), species for which ice-free conditions are favourable:

A comparison with the temperature curves shows that the catch of Narwhal (and White Whale) in the northern districts of West Greenland follows the positive fluctuations of the temperature.

(Vibe 1967: 74)

Vibe's analysis is revealing about both the effects of climate/sea-ice changes on two species critical to Inuit subsistence and the adaptive capacity of the Inuit. As noted earlier, in terms of the contemporary Canadian Inuit subsistence system, ringed seals and, as will be discussed below, polar bears are as important as at any time in the past to the economic well-being of small Nunavut communities (Wenzel 1991). In this system, the ringed seal, or natsiq, is one of the principal items in the Inuit diet (Wenzel 1991; NWMB 2004). Ringed seals are present in significant numbers throughout the waters of Nunavut. Just as importantly, unlike many other whales and seals that are only present during times of open water, ringed seals are resident all year round. Finally, they provide high-quality nutrition when few alternatives, except the most costly imported foods, are available.

The importance of the ringed seal is illustrated by its role in the food economy of Clyde River. There, ringed seal comprises approximately $54 \%$ of the edible biomass captured annually by Clyde hunters (Wenzel 1991: 81, 82). Furthermore, its importance is made even more apparent when the seasonal dietary contribution of the seal is calculated in relation to caribou, the next most important food species in that community. In these terms, seal represents $58 \%$ of the winter food supply, and $70 \%$ of the food supply from spring through to autumn, whereas caribou contributes 39\% of the winter food captured, and just $21 \%$ of the total subsistence production in the other three seasons. In the ecological economics of Inuit life, the impact on subsistence that might result from any substantial reduction of the seal harvest would be potentially serious.

A severe reduction in the abundance of ringed seal as a result of climate-related changes in the range, distribution and local densities of the species would adversely affect at least the Inuit winter food economy as, at present, there is no other species present on the land or in the waters of Nunavut that are as abundant or as available as the ringed seal. Concomitantly, a serious reduction or absence of ringed seal would affect the ningiqtuq, because seal and other meats are literally the mainstay of the sharing system, and thus are the cultural, as much as 
the material, substance of Inuit subsistence. To hunt, catch and share food is the essence of living Inuktitut (see Wenzel et al. 2000), and the ringed seal, because of its abundance, epitomizes this.

Polar bear also play an important role in the contemporary subsistence system. Like seal, it, too, is niqituinnaq. But, as Vibe's analysis showed, climate change can have as serious an affect on polar bears as it has on ringed seals (also see Laidre et al. 2008), and therefore on Inuit subsistence, albeit differently than in the case of the ringed seal.

Although bears are an important seasonal food, because they are limited in overall numbers (several tens of thousands versus hundreds of thousands of ringed seals) and subject to strict conservation management, the material contribution of the polar bear to Inuit diet relates to how it is valued by the non-Inuit. In the contemporary subsistence system, polar bears represent one of the few sources of money that the Inuit can earn through the practice of traditional skills (Wenzel in press). This is mainly through the sale to non-Inuit sport hunters of a portion of the annual quota provided to the Inuit (some 425 bears). The sport hunt, although only receiving about $18-20 \%$ of the quota (77-90 permits in any year), injects about 1.8-2.0 million Canadian dollars (CAD) directly into the hands of the Inuit living in Nunavut's smaller communities.

Linking subsistence seal hunting and polar bear sport hunting may seem spurious-seals are food, whereas polar bears, when the right to hunt them is sold to wealthy trophy seekers, are seemingly reduced to the status of a commodity. But this ignores an important aspect of modern Inuit subsistence, namely that hunters must confront how to gain access to money at a minimum cost of time. Although hunting produces large quantities of high-quality food-the Government of Nunavut estimates that to substitute imported food for niqituinnaq would cost approximately 35000000 CADvirtually none of this traditional "wealth" brings the money needed to purchase, operate and maintain a hunter's essential equipment.

Polar bear sport hunting helps meet the cash resource needs of many hunters while imposing a minimal cost in time. In 2004, 10 sport polar bear hunts at Clyde River brought approximately $225000 \mathrm{CAD}$ into the community, altogether more than twice the income that entered the community from four years of hikers, skiers, kayakers and other ecotourists. More than half of this went directly into the hands of the Inuit who were otherwise full-time hunters. These men then purchased an array of equipment, including snowmobiles, boats and engines, and other equipment, plus fuel and ammunition, costing $110000 \mathrm{CAD}$, for use in seal hunting and other subsistence activities.
The importance of sport hunt income to subsistence becomes even clearer when the earnings of guides are translated into harvested food. Six Clyde hunters, who also work as polar bear trophy guides, captured some 240 ringed seals, 42 caribou and 15 narwhal, totalling $6275 \mathrm{~kg}$, or almost $1050 \mathrm{~kg}$ per hunter per year (Wenzel in press). Replacing this production with imported meat bought at the retail store in Clyde River would cost almost $63000 \mathrm{CAD}$. Through guiding, the return per dollar of sport hunt income to food produced was, on average, five-fold ( $1: 5.3)$.

\section{Can traditional subsistence be sustained?}

If the warming trajectory projected for the North is correct, communities in at least the southern portions of Nunavut may find traditional subsistence resources, like the ringed seal, to be negatively affected. This possibility has led to considerable concern about the capacity of Inuit to adapt to global warming, notably with respect to subsistence (Nuttall et al. 2005; Ford et al. 2006).

There is no clear answer as to whether the Inuit will successfully adapt to the changes that are expected, notwithstanding Jamasee Qillaq's remark about global warming, which opened this paper. As Vibe's Greenland work shows, a serious reduction in the extent and duration of sea ice can affect ringed seals and polar bears, which, given the contributions of these species to the subsistence system as food, or because of their monetary value, could pose a threat to both the production (hunting) and cultural (ningigtuq) components of the traditional economy.

On the other hand, it is also clear that the Inuit took what advantage they could in the warmer periods of the past, by exploiting those species that found the new conditions to be beneficial. That Qillaq was waiting for narwhal to appear nearly a month ahead of their expected time suggests that the Inuit will make similar adjustments now. In fact, his statement exactly summarized the Inuit adaptation to change, in shifting their harvesting strategies towards familiar but previously rare resources. As that summer progressed, and harp seals appeared in the nearby fjord, Clyde River hunters also incorporated the harp seal, normally only found in the open ocean of Baffin Bay because of the ice in local fjords, as a supplement to ringed seals. In this behaviour, Clyde River is not an isolated case. Ford et al. (2006) likewise suggest the potential benefits of changes in sea-ice cover for the Inuit in other parts of Nunavut, as changes in the environment create other kinds of hunting opportunities.

Nunavummiut are likely to increase their harvest of species favoured by conditions such as longer periods of open water (and in fact, may already be doing so; see 
Diduck et al. 2005: 275), much as Vibe's analysis suggests was done by Greenlanders. It is also possible that terrestrial resources, notably caribou and musk ox (Ovibos moschatus), may assume enlarged contributory roles as the production aspect of the subsistence system adjusts.

These kinds of shifts make good tactical sense in several respects. Ecologically, "replacement" species like narwhal, beluga whales and harp seal are all larger packages of energy than the ringed seal, and so can provide a greater return for hunters' efforts. Another benefit is that male narwhal have ivory tusks presently valued at $300 \mathrm{CAD}$ per metre (or, like walrus ivory, 100 CAD per pound [ca. $454 \mathrm{~g}$ ]), which can help with a monetary shortfall should polar bear become less available. In fact, a small sport hunt market (see Chivers 2002) has already emerged for walrus. Third, narwhal and beluga provide maqtaaq, a highly favoured traditional food, of which the Inuit would welcome larger supplies. Similarly, caribou might ease a reduction in ringed seals, depending on conditions in the terrestrial environment, such as a northward-moving treeline shifting caribou wintering grounds closer to some Inuit communities. Finally, harp seals, having recovered from heavy exploitation by the non-Inuit, and now appearing in large numbers in eastern Arctic waters, might gain subsistence importance, although they are not now a preferred Inuit food when ringed seal is available.

Although adjustments in resource focus are a logical adaptive move, and are consistent with past Inuit responses to environmental changes, it is by no means clear how secure the utilization of such "fallbacks" will be. For instance, caribou, now the terrestrial species most widely exploited by the Inuit, are highly sensitive to the kinds of wet-cool conditions that may occur if rain precedes the autumn freeze, rather than snow, thereby icing over vegetation, and thus preventing the caribou from obtaining winter food (see Kattsov et al. 2005: 127). Exactly this situation, albeit on a limited scale, occurred in 1972 (see Kemp et al. 1978) on several islands in the High Arctic. The result was that Peary caribou disappeared for nearly six years from the Bathurst and Cornwallis islands.

The present reduced state of Peary caribou, serious enough for a number of central Arctic communities to have limited the subsistence harvests of the species (see Collings 1997; Miller \& Gunn 2003), may also have been triggered by autumn rains that iced the winter food supply and crusted the snow cover. Coevally, in much of the Canadian Arctic Islands, and on parts of the mainland, musk ox, which are better adapted to these conditions, have supplanted caribou, but, as evidenced by the depletion of musk ox during the late 19th and early 20th centuries by non-Inuit explorers and sportsmen, they are highly vulnerable to overexploitation.
In the marine environment, the potential impact of global warming on polar bears and ringed seals in southern parts of their ranges has already been documented (Laidre et al. 2008). However, Heide-Jørgensen \& Laidre (2004) noted that eastern Arctic narwhal may be adversely affected by the shrinkage of the mid-Baffin Bay polynya, where the animals find relatively ice-free waters between November and April, as a result of colder winter temperatures.

As the above discussion makes clear, just how change in the northern biophysical system will affect wildlife, and, as a result, the Inuit is difficult to evaluate, as there are too many yet unfactored variables. What is clear, however, is how different the present environment that the Inuit must adapt to is compared with the environment of 50 years ago, let alone compared with that of a millennium ago, when the Thule people crossed from Alaska to Greenland. In point of fact, the contemporary Arctic environment is characterized as much by a political atmosphere that could exert severe constraints on the adaptive efforts of the Inuit as it is by warmer temperatures and the earlier break-up of sea ice. Whatever ecological issues may affect the degree to which narwhal, harp seals or other, more novel, species can be incorporated into or take on enlarged roles within the subsistence system, the political nature of climate change has already become a factor. And, as the Inuit know well from the seal controversy of the 1980s (Malouf 1986; Wenzel 1991; Lynge 1992), concern for the well-being of one species can translate into opposition to the Inuit subsistence use of another.

The situation is even more complex when a species takes on the status of an environmental icon. This was the case with harp seal pups in the seal controversy, and is happening currently with the polar bear, as it becomes the "poster species" for the catastrophe predicted to lie ahead because of global warming (Wenzel in press). The Inuit have already learned that even the best scientifically regulated use of a species is likely to be insufficient to mollify political concerns for charismatic animals.

\section{Conclusions}

With regard to the breadth of freedom that the Inuit have to adapt to the ecosystem changes occurring in the Arctic, it is clear that at least one of the alternatives that may have been followed by their forebears is not viable. The mobility that the Thule and Little Ice Age ancestors of today's Nunavummiut possessed, i.e., moving in response to shifts in the pattern and state of their resource base, is now prisoner to the fixed communities that are the result of Canadian governmental policies. Overall, Canada has invested hundreds of millions of dollars in Nunavut, 
Northwest Territories and Nunavik, developing modern, if modest, housing, nursing stations, airports, telecommunications and industrial facilities. Clyde River, for instance, which is home to about 850 Inuit, and is more or less representative of the kind of facilities and services found across Nunavut, has reached its present state of facilities and services as a result of the 75000000 $100000000 \mathrm{CAD}$ that have been spent over the last three and a half decades by the federal and two territorial governments. In today's political/economic climate, reconstituting this investment anew because of Inuit migration to remain in contact with ringed seals or polar bears, so that a traditional subsistence culture can be maintained, is not likely to receive a moment of policy makers' consideration.

Despite the concerns that have been voiced about the abilities of the Inuit to adapt to vulnerabilities to the traditional food system as climate-related changes affect wildlife populations, Jamasee Qillaq and his fellow Nunavummiut began the process almost before all but a small body of scientists knew of, let alone took seriously or spoke out about, the issue of global warming. Indeed, Inuit culture has shown that it is well equipped in its ability to adapt to the far more disconcerting changes to the northern environment caused by the tsunami of economic and social change that has occurred in the northern sociocultural environment in the last half-century. With respect to climate change and the accompanying ecological changes that may affect Inuit subsistence, it is worth remembering that they have an experiential baseline that spans a millennium of adaptation.

However, this is not to say that what is occurring in the Arctic will not present the Inuit, and the non-Inuit, with challenges. If allowed, the Inuit will exploit those new species, like harp seals, that may at least partially fill the new niches that global warming will create. They will also expand their utilization of more traditional animals, like narwhal and beluga, as ecosystem changes increase their availability.

But, these transitions will be minor compared with the real adaptive challenge that will confront the Inuit. As concern about the impacts of climate change grow worldwide, and especially among Europeans, Americans and southern Canadians, the Inuit will find that the many effective local-level adaptive responses will conflict with non-Inuit attitudes about wildlife conservation, sustainability and environmental management. The Inuit have lived with stringent regulations on their use of polar bear, walrus and small cetaceans since the 1970s, and have had the experience of having their reliance on their most important marine mammal resource, ringed seals, come under attack (see Wenzel 1991; Lynge 1992). As the recent elevation of the polar bear to threatened status under the United States Endangered Species Act indicates, the Inuit will almost certainly bear the brunt of non-Inuit perceptions about imperiled Arctic wildlife, or, worse, that the Inuit are "behaving non-traditionally".

The crucial adaptive problem is not the fate of polar bears or seals, nor which species may fill the newly vacated niches, but rather how the global environmental political regime will respond to Inuit ecological choices. What the Inuit must make clear is that their "subsistence adaptation" is not only about how to maintain the hunting component of the system, but also, and perhaps more importantly, how to sustain the social economy of ningiqtuq when well-meant decisions in Washington, London, Geneva and Brussels about polar bears, narwhals and caribou are ignorant of their cultural impact.

All this is to say that the environment to which the Inuit must adapt is a far more complex one than the one experienced by their Thule forebears. On the other hand, as the Inuit increasingly find their own political voice, they must make negotiation part of their adaptive toolkit.

\section{References}

Andrews M. \& Andrews J.T. 1979. Bibliography of Baffin Island environments over the last 1000 years. In A. McCartney (ed.): Thule Eskimo culture: an anthropological retrospective. ASC Mercury Paper No. 88. Ottawa: National Museum of Man.

Barry R., Arundale W., Andrews J.T., Bradley R. \& Nichols H. 1977. Environmental and cultural change in the eastern Arctic during the last five thousand years. Arctic and Alpine Research 9, 193-210.

Boas F. 1888. The Central Eskimo. In J.W. Powell (ed.): Sixth annual report of the Bureau of American Ethnology to the Secretary of the Smithsonian Institution 1884-1885. Pp. 399-669. Washington D.C.: Government Printing Office.

Briffa K., Bartholin T., Eckstein D., Jones P., Karlen W., Schweingruber F. \& Zetterberg P. 1990. A 1400-year tree-ring record of summer temperatures in Scandinavia. Nature 346, 434-439.

Chivers C.J. 2002. A big game. New York Times Magazine, 25 August.

Collings P. 1997. Subsistence hunting and wildlife management in the central Canadian Arctic. Arctic Anthropology 34, 41-56.

Collings P., Wenzel G.W. \& Condon R. 1998. Modern food sharing networks and community integration in the central Canadian Arctic. Arctic 51, 301-314.

Damas D. 1963. Iglulingmiut kinship and local groupings: a structural approach. Bulletin 196. Ottawa: National Museum of Canada.

Damas D. 1972. Central Eskimo systems of food sharing. Ethnology 11, 220-240.

Damas D. 2002. Arctic migrants. Arctic villagers. The transformation of Inuit settlement in the central Arctic. Montreal: McGill-Queen's University Press. 
Dekin A. 1972. Climate change and cultural change: a correlative study from eastern Arctic prehistory. Polar Notes $12,11-31$.

Diduck A., Bankes N., Clark D. \& Armitage D. 2005. Unpacking social learning in social-ecological systems: case studies of polar bear and narwhal management in northern Canada. In F. Berkes et al. (eds.): Breaking ice: renewable resource and ocean management in the Canadian North. Pp. 269-290. Calgary: University of Calgary Press.

Dyck M., Soon W., Baydack R., Legates D., Baliunas S., Ball T. \& Hancock L. 2007. Polar bears of western Hudson Bay and climate change: are warming spring temperatures the "ultimate" survival control factor? Ecological Complexity 4(3), 73-84.

Fienup-Riordan A. 1986. When our bad season comes. A cultural account of subsistence harvesting and harvest disruption on the Yukon Delta. Anchorage: Alaska Anthropological Association.

Ford J., Smit B. \& Wandel J. 2006. Vulnerability to climate change in the Arctic: a case from Arctic Bay, Canada. Global Environmental Change 16, 145-160.

Ford J., Smit B., Wandel J., Allurut M., Shappa K., Ittusarjuat H. \& Qrunnut K. 2008. Climate change in the Arctic: current and future vulnerability in two Inuit communities in Canada. The Geographical Journal 174, 45-62.

Grove J. 1988. The Little Ice Age. New York: Methuen. Heide-Jørgensen M. \& Laidre K. 2004. Declining extent of open-water refugia for top predators in Baffin Bay and adjacent waters. Ambio 33, 487-494.

Heinrich A. 1963. Eskimo-type kinship and Eskimo kinship: an evaluation and provisional model for presenting data pertaining to Inupiaq kinship systems. PhD thesis, University of Washington, Seattle.

Kattsov V., Kallén E., Cattle H., Chrustensen J., Drange H., Hanssen-Bauer I., Jóhannesen T., Karol I., Räisänen J., Svensson G., Vavulin S., Chen D., Polyakov I. \& Rinke A. 2005. Future climate change: modeling and scenarios for the Arctic. In C. Symon et al. (eds): Arctic climate impact assessment. Pp. 99-150. Cambridge: Cambridge University Press.

Kemp W., Wenzel G.W., Val E. \& Jensen N. 1978. A socioeconomic baseline study of Resolute Bay and Kuvinaluk. Toronto: Polargas Project.

Laidre K., Stirling I., Lowry L., Wiig O., Heide-Jorgensen M.P. \& Ferguson S. 2008. Quantifying the sensitivity of Arctic marine mammals to climate-induced habitat change. Ecological Applications 18(2), S97-S125.

Lamb H. 1982. Climate, history, and the modern world. London: Methuen.

Lonner T. 1980. Subsistence as an economic system in Alaska: theoretical and policy implications. Technical Paper No. 67. Anchorage: Division of Subsistence, Alaska Dept. of Fish and Game.

Lynge F. 1992. Arctic wars, animal rights, endangered peoples. Hanover, NH: University of New England Press.
Malouf A. 1986. The campaign against sealing. In: Seals and sealing in Canada: report of the Royal Commission. Vol. 2. Pp. 65-101. Ottawa: Supply and Services Canada.

Mann N., Bradley R. \& Hughes M. 1999. Northern Hemisphere temperatures during the past millenium: inferences, uncertainties, and limitations. Geophysical Research Letters 26, 449-471.

Maxwell M. 1985. Prehistory of the eastern Arctic. New York: Academic Press.

McBean G., Alekseev G., Chen D., Forland E., Fyfe J., Groisman P., King R., Melling H., Vose R. \& Whitfield P. 2005. Arctic climate: past and present. In C. Symon et al. (eds.): Arctic climate impact assessment. Pp. 21-60. Cambridge: Cambridge University Press.

McGhee R. 1972. Climatic change and the development of Canadian Arctic cultural traditions. In Y. Vasari et al. (eds.): Climatic change in Arctic areas during the last ten thousand years. Pp. 39-57. Oulu: University of Oulu.

McGhee R. 1996. Ancient peoples of the Arctic. Vancouver: University of British Columbia Press.

Miller F. \& Gunn A. 2003. Catastrophic die-off of Peary caribou on the western Queen Elizabeth Islands, High Arctic, Canada. Arctic 56, 381-390.

Nuttall M., Berkes F., Forbes B., Kofinas G., Vlassova T. \& Wenzel G.W. 2005. Hunting, herding, fishing and gathering: indigenous peoples and renewable resource use in the Arctic. In C. Symon et al. (eds.): Arctic climate impact assessment. Pp. 660-702. Cambridge: Cambridge University Press.

NWMB (Nunavut Wildlife Management Board) 2004. The Nunavut wildlife harvest study. Iqaluit, NU: Nunavut Wildlife Management Board.

Pfister C. 1988. Variations in the spring-summer climate of central Europe from the high Middle Ages to 1850. In H. Wanner \& U. Siegenthaler (eds.): Long and short term variability of climate. Berlin: Springer.

Savelle J. \& Wenzel G.W. 2003. Out of Alaska: reconstructing the social structure of prehistoric Canadian Thule culture. In J. Habu et al. (eds.): Hunter-gatherers of the North Pacific Rim. Pp. 103-121. Osaka: National Museum of Ethnology.

Stirling I. \& Øritsland N. 1995. Relationships between estimates of ringed seal (Phoca hispida) and polar bear (Ursus maritimus) populations in the Canadian Arctic. Canadian Journal of Fisheries and Aquatic Sciences 52, 2594-2612.

Vasari Y., Hyvärinen H. \& Hicks S. (eds.) 1972. Climatic change in Arctic areas during the last ten thousand years. Oulu: University of Oulu.

Vibe C. 1967. Arctic animals in relation to climatic fluctuations. Meddelelser om Grønland 170(5). Copenhagen: C.A. Reitzels.

Wenzel G.W. 1981 Clyde Inuit ecology and adaptation: the organization of subsistence. Canadian Ethnology Service Mercury Paper No. 77. Ottawa: National Museums of Canada.

Wenzel G.W. 1989. Sealing at Clyde River, N.W.T.: a discussion of Inuit economy. Etudes/Inuit /Studies 13, $3-23$. 
Wenzel G.W. 1991. Animal rights, human rights: ecology, economy and ideology in the Canadian Arctic. Toronto: University of Toronto Press.

Wenzel G.W. 1995. Ningiqtuq: Inuit resource sharing and generalized reciprocity in Clyde River, Nunavut. Arctic Anthropology 32, 43-60.

Wenzel G.W. 2000. Sharing, money, and modern Inuit subsistence: obligation and reciprocity at Clyde River, Nunavut. In G.W. Wenzel et al. (eds.): The social economy of sharing: resource allocation and modern hunter-gatherers. Pp. 61-85. Osaka: National Museum of Ethnology.

Wenzel G.W. 2004. Sharing. In M. Nuttall (ed.): Encyclopedia of the Arctic. Pp. 491-494. London: Routledge.
Wenzel G.W. in press. Sometimes hunting can seem like business: polar bear sport hunting in Nunavut. Edmonton: CCI Press.

Wenzel G.W., Hovelsrud-Broda G. \& Kishigami N. 2000. Introduction. In G.W. Wenzel et al. (eds.): The social economy of sharing: resource allocation and modern hunter-gatherers. Pp. 1-6. Osaka: National Museum of Ethnology.

Wenzel G.W. \& White L.-A. 2001. Chaos and irrationality(!): money and Inuit subsistence. Paper presented at the International Congress of Arctic Social Scientists, 16-20 May, Québec City. 